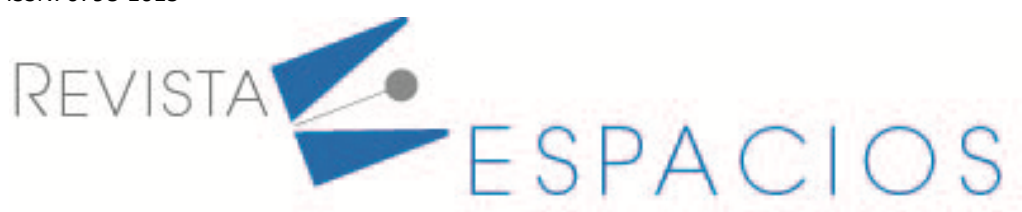

\title{
Study of TV white spaces in the context of cognitive radio for the deployment of WiFi in rural zones of the colombian army
}

\section{Estudio de espacios en blanco de TV en el contexto de radio cognitiva para el despliegue de WiFi en zonas rurales del ejército colombiano}

\author{
AVENDAÑO, Eduardo ${ }^{1}$ \\ ESPINDOLA, Jorge E. ${ }^{2}$ \\ MONTAÑEZ, Oscar J. ${ }^{3}$
}

\begin{abstract}
This article presents a study on Television White Spaces (TVWS) to solve the connectivity of the WiFi service for the Colombian National Army in rural areas. The study analyzes regulatory aspects and technical equipment to provide a free internet access solution. Video transmission was experimentally validated, using OFDM with USRP N210 radios. With this preliminary analysis, it was possible to understand how the PHY and MAC layers of the 802.22 Standard work to select the appropriate devices.

key words: tvws, usrp, cognitive radio, software-defined radio (sdr)

Resumen

Este artículo presenta un estudio sobre Espacios Blancos de Televisión para solucionar la conectividad del servicio WiFi para el Ejército Nacional de Colombia en zonas rurales. El estudio analiza aspectos regulatorios y el equipamiento técnico para brindar solución de acceso gratuito a internet. Se validó experimentalmente la transmisión de video, usando OFDM con radios USRP N210. Con este análisis preliminar, fue posible comprender cómo funcionan las capas PHY y MAC del Estándar 802.22 para seleccionar los dispositivos adecuados.

Palabras clave: tvws, usrp, radio cognitiva, radio definida por software (sdr)
\end{abstract}

\section{Introduction}

Wireless telecommunication systems have experienced an increasing evolution due to higher data traffic demanded by the users over the networks that exceed the capacity of individual fiber communication systems (Mitola \& Maguire, 1999). To cope with this demand for capacity, the actual efforts are focused on potential technological candidates based on digital signal processing techniques to provide a dramatic increase in capacity or improve the energy of transmission. This thinking looks to assure cost-and-energy efficient communication networks. The TV white space (TVWS) technology was considered after the transition from analog to digital

\footnotetext{
${ }^{1}$ Associate professor. Electronic Engineering Program, GINTEL Research Group, Universidad Pedagógica y Tecnológica de Colombia. Contact e-mail: eduardo.avendano@uptc.edu.co

${ }^{2}$ UPTC Professor and researcher at the GICMIL Military Communications Research Group of the ESCOM Communications School of the Colombian Army located in Facatativá. Contact e-mail: jespindola@uptc.edu.co

${ }^{3}$ Assistant researcher. GINTEL Research Group, Universidad Pedagógica y Tecnológica de Colombia. Contact e-mail: oscarjavier.montanez@uptc.edu.co
} 
television in some countries, as an alternative for using the free spaces in the spectrum to provide internet access, especially in rural areas, without causing interference to licensed users (Primary Users - PU) of television channels transmitting at low-power levels and low-cost equipment.

The Cognitive Radio (CR) (Q. Zhao \& Sadler, 2007), (Borth et al., 2008) technology has been enabled by the application of Software Defined Radio (SDR) (Haykin, 2005) communication systems and has a lot of research interest due to the opportunity to develop devices and equipment holding important advantages over some other wireless transmission standards mainly during transmission; since the 802.11af IEEE standard, uses lower frequencies $(470 \sim 800 \mathrm{MHz}$ ) than the traditional Wi-Fi frequencies $(2.5 \mathrm{GHz}$ or $5 \mathrm{GHz}$ ), achieving much better signal propagation performance. Besides, it attains an increased reach, improves the transmission data rate, and can cross obstacles mitigating the multipath losses using the Orthogonal Frequency Division Multiplexing (OFDM) access technique, within others.

Globally, research has been conducted on TVWS specifically on topics such as free internet for citizens, dynamic allocation in real-time of blank spaces within the TV bands, and plan deployments, among other aspects of interest. Colombia was the first country in South America that regulates TVWS technology. This effort was carried out by the ANE (National Spectrum Authority) and the Dynamic Spectrum Alliance (DSA). This is one alternative to explore the use of the spectrum to allow access to people without connection in Colombia. Hence, the study for the implementation of TVWS technology in the Colombian National Army, to bring internet to rural areas where their troops operate is an important objective in the development of the country to offer education to the population in zones where there is no connectivity. From the transition of analog television services towards the digital terrestrial television (DTT), it was identified that there are many unused frequencies (the very highfrequency (VHF)/ultra high-frequency (UHF) bands) in certain areas of the world.

An analog TV channel has a $6 \mathrm{MHz}$ bandwidth, within this same bandwidth of one analog channel it can be handled from 3 up to 10 digital channels. This multiplicative factor improves the overall efficiency of the spectrum and energy used in the transmission process. In some regions, the analog TV spectrum would provide approximately $300 \mathrm{MHz}$ extra of spectrum bandwidth with the opportunity for not only TV and WiFi services, but the Internet of Things (IoT), Big Data/Small Data analytics using geolocation databases with the need of regular updates regarding the available TVWS channels, and the 5G-LTE that requires to facilitate the coexistence of many wireless devices with increased device and services complexity and also ubiquitous access to mobile services (Anabi et al., 2016).

The first Latin American country that approves the use of TVWS technology was Colombia in 2017. However, the regulatory framework for the use of the wireless data transmission technology, known as the IEEE WRAN 802.22 standard, which was promoted globally by non-governmental organizations (NGOs) and the DSA, was approved in 2010 by the US Federal Telecommunications Agency (FCC Nekovee, 2010), (Wang et al., 2010). Under this concept, the Colombian NSA has adopted the database-assisted TVWS that enables the spectrum reuse paradigm throughout the country.

In this paper, a feasibility study of different technological solutions in the market is evaluated under the technical specifications of the IEEE WRAN 802.22 standard. In section II, a general description of the WRAN 802.22 standard and the key design objectives and protocol architecture are synthesized, then in section III, the spectrum sensing models are reviewed making a special effort on the new trends of detection based on energy and eigenvalues. In section IV, an experiment as a proof-of-concept for video transmission and analysis of different technical solutions on the market was used to evaluate the feasibility of deploying WiFi access in a rural zone of a military base of the Colombian Army. Finally, a general conclusion summarizes the results of the study and future work. 


\section{Wireless Regional Area Network (WRAN) IEEE 802.22 Standard}

Cognitive radio technology (CR) (Q. Zhao \& Sadler, 2007), (Ko et al., 2011), promises efficient use of the available spectrum. In this context, rules proposed by the Federation of Communications Commission (FCC) propose that unlicensed radios (secondary users) can operate in television broadcasting bands (primary users) without generating harmful interference to the incumbent services, this as a consequence of the transition of analog technology in television services, that migrate to digital terrestrial television releasing portions of the spectrum according to the advantages of digital systems, and that are known as white spaces for digital television (TVWS) (Nekovee, 2010). In (Wang et al., 2010) the first CR standard for personal/portable devices on TVWS is presented. The current state of political discussions regarding spectrum management in regulatory agencies worldwide is introduced, and a detailed description of the industry association for standardization, communication, and information technologies, and consumer electronics (ECMA) 392, for personal/portable devices, which includes the Physical Layer (PHY) and Medium Access Control (MAC) layers architecture.

According to Mitola (Mitola \& Maguire, 1999), the radio tag is a set of radio frequency (RF) bands, Air interfaces, protocols, and temporal and spatial patterns that moderate the use of radio spectrum. CR improves the flexibility of personal devices using a radio knowledge representation language (RKRL). In other words, with the RKRL, intelligent agents aware of the radio domain supported by the RC, can actively manipulate the protocol stack to accommodate known labels that best meet the user's needs. Therefore, (Martin et al., 2008) shows that a protocol based on IEEE $802.16 \mathrm{e}$ or a similar wireless broadband protocol could be adapted to meet the needs in this space. In some rural markets, a spectrum of up to $250 \mathrm{MHz}$ could be used (Borth et al., 2008). Expected initial system deployments at TVWS include internet service providers and broadband coverage systems for business enterprises. Existing protocols such as WiMax, WiFi, and proprietary protocols are reallocated in-band to UHF ranges, which will provide broadband data performance inadequate ranges to enable practical services. The American FCC and the British regulator's office of communications (OfCom) (Nekovee, 2010) have considered three methods to ensure that cognitive devices do not cause harmful interference to incumbents: beacons (intermittent control signal), combined geolocation (Gurney et al., 2008) with access to a database (DB), and sensing.

Figure 1 shows the operating cycle of the IEEE 802.22 standard in the case of TVWSs. In the sensing method stage, standalone devices detect TV signals and only use channels that are not used for TV service deployment. This scenario is limited to the hidden node problem due to blocking between the unlicensed device and a TV station, but without blocking between the TV station and a TV receiver antenna, as well as between the unlicensed device and the TV receiver. 
Figure 1

TVWSs stage operation

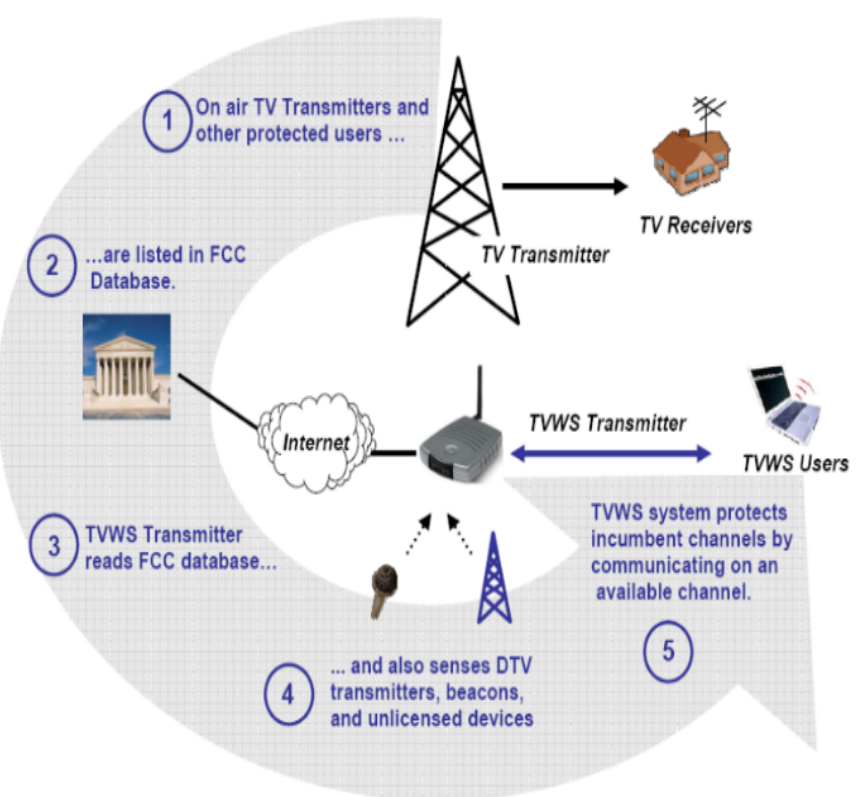

Source: (Borth et al., 2008)

\subsection{Standardization and Industry Efforts}

The research-driven by the industry and the development of cognitive radio technology has been managed so that new players (Google and Microsoft) gain access to the TVWS that have been released in the United States since 2010. The Cognitive Network Alliance Standard (CogNeA) (Nekovee, 2010), is an open industry association that aims to market CR platforms for low-power personal/portable devices by enabling and promoting rapid adoption, regulation, standardization, multi-vendor compliance, and CR interoperability worldwide. CogNeA also seeks to develop specifications for the Common Cognitive Radio Platform (CCRP) (Amor Nafkha, 2011), (Masonta et al., 2012) at the PHY and MAC layers, which supports multiple applications for unlicensed broadband wireless access for communities/neighborhoods/campuses. Furthermore, the Standardization, Information and Communication Technology, Consumer Electronics, Industry association (ECMA) developed a standard that employs a CR for DB sensing and technology to avoid interference with licensed services and other incumbent users following FCC rules.

The IEEE 802.22 working group defined the standard with the physical (PHY) and medium access control (MAC) interfaces for regional area networks (WRAN) based on CR techniques. The main objective of applying the standard is license-free broadband internet access in rural areas using the TVWSs (FCC, 2019). The 802.22 system specifies a point-to-multipoint wireless air interface where a base station (BS) manages its cell and all associated consumer premise equipment (CPEs). The network architecture including PHY and MAC were derived from the IEEE 802.16 WiMax standard (Alsharbaty et al., 2019). The 802.22 PHY layer was designed to support a system that uses the available channels of TVWS to provide wireless access over distances of up to $100 \mathrm{~km}$, using Orthogonal Frequency Division Multiple Access (OFDMA) technology (Koffman \& Roman, 2002), (Morelli et al., 2007). The IEEE 802.22 standard supports incumbent detection through spectral sensing (the DB approach is optional) by specifying inputs and outputs, as well as performance requirements for the implemented sensing algorithms (for example, probability of detection, incumbent detection threshold and the probability of false alarm). Those methods include the power detector, cyclo-stationary, and pilot sensing detectors for digital TV signals from the Advanced TV Systems Committee (ASTC). 
The IEEE 802.22 standard (Mody, 2020) defines two important capabilities at the MAC layer to support reliable sensing-based detection of incumbents (Gurney et al., 2008): long network sensing periods scheduled by each BS during all transmissions that must be suspended to allow Reliable sensing and management of channel measurements to coordinate distributed measurement/incumbent detection by CPEs and their reporting to the BS. Figure 2 shows the architecture of the reference protocol for a BS 802.22 or CPE. Regarding the PHY layer, there are three primary functions.

Figure 2

Protocol architecture of reference for an 802.22 BS or CPE

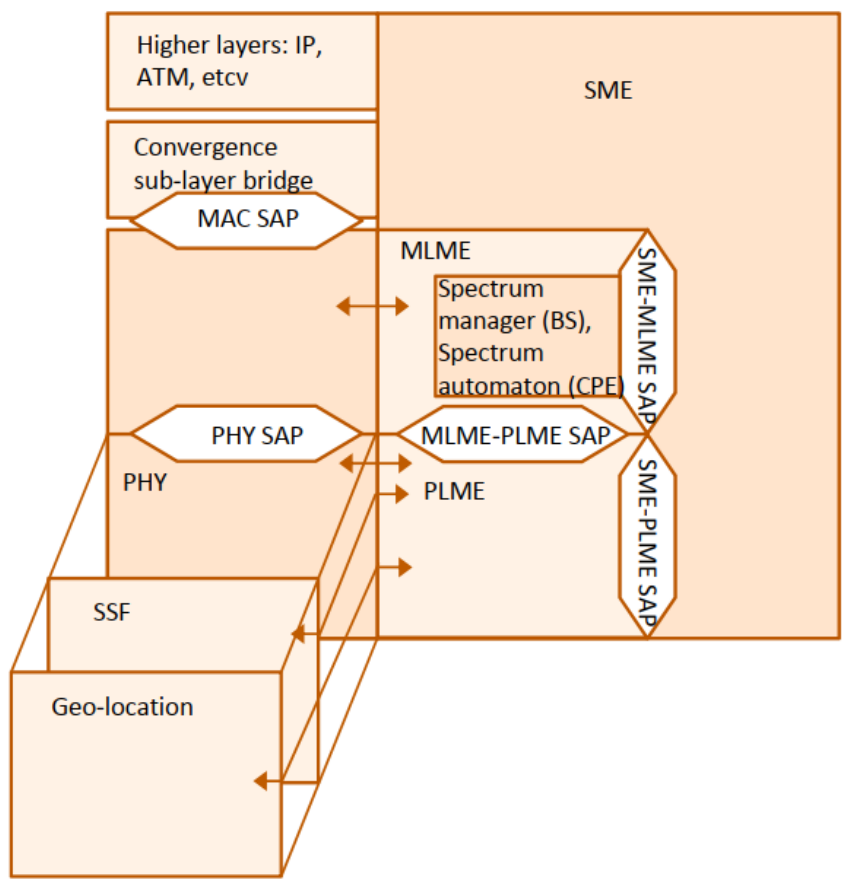

Source: (Mody, 2020)

In data communications, the spectrum sensing function (SSF) and the geolocation function enable the cognitive abilities of the system. For its part, the MAC layer coordinates access to the medium, and the upper layers, such as the internet protocol (IP), asynchronous transfer mode (ATM), and the IEEE 1394 protocol through the convergence sublayer according to 802.1d.

\subsection{Operational Architecture for the TVWS Scenario}

The IEEE 802.22 standard operates in low population density areas, provides wideband access to data networks taking advantage of TV channel availability in very high-frequency bands (VHF) and ultra-high frequency bands (UHF), in the range from $54 \mathrm{MHz}$ up to $862 \mathrm{MHz}$. Particularly operates as free-license equipment, despites the base station and the CPE must be installed by professionals.

\section{Basic Requirements}

The main benefit of the TVWSs rises from better propagation conditions, an improvement on the range and robustness when comparing to higher frequencies for the service offers, in particular, to complement the quality in the response to emergencies and the public network services. The ability to operate under low power level increases the energy efficiency level. In this sense, the technical requirements have been redirected to support 
these characteristics by providing video diffusion to the home in a reliable way. The channel model for propagation in UHF has been characterized properly, but in Colombia, a particular analysis is required due to its particular orography. Besides, the path loss and losses due to wall absorption, and multi-path, are key aspects of channel propagation in indoor scenarios.

\section{- PHY layer}

Concerning the PHY layer, it is designed to support the available TV channels and to provide access to wireless communications over distances up to $1000 \mathrm{~km}$. It uses OFDMA for the upstream from the CPE towards the BS at a rate of $384 \mathrm{~kb} / \mathrm{s}$, and the downstream from the $B S$ towards CPE at a rate of $1.5 \mathrm{Mb} / \mathrm{s}$. The link margin values for the lowest and highest data rate modes targeted by the standard are shown in Table 1 (It is assumed a transmit power of $20 \mathrm{dBm}$ and a path loss exponent of 2). A key element in the table is the link margin for the lower and higher modes defined by the standard.

\section{- MAC layer}

In the MAC layer, the frame and superframe structures have been developed, incumbent detection, multichannel operation, auto-coexistence, and quality of service (QoS) support. The timing synchronization structure, where the frames are grouped into superframes allows improving the protection against incumbents and coexistence.

Table 1

Link Margin and System Parameter Specifications

\begin{tabular}{|l|l|}
\hline \multicolumn{1}{|c|}{ Parameter } & \multicolumn{1}{c|}{ Specifications } \\
\hline Frequency range & $54-862 \mathrm{MHz}$ \\
\hline Bandwith & 6,7 y $8 \mathrm{MHz}$ \\
\hline Modulation payload & QPASK, 16-QAM y 64-QAM \\
\hline Effective isotropic radiated power transmitted & By default 4W for the CPE \\
\hline Multiple Access & OFDMA \\
\hline Cyclic prefix mode & $1 / 4,1 / 8,1 / 16$ y 1/32 \\
\hline Duplexation technique & Time división duplexation (TDD) \\
\hline Data Rate & $4.75-23.74 \mathrm{Mb} / \mathrm{s}$ \\
\hline Average transmission power & $20 \mathrm{dBm}$ \\
\hline Total Path-loss $(f=600 \mathrm{MHz})$ & $88 \mathrm{dBm} @ 1000 \mathrm{~m}$ y 68 dBm@100m \\
\hline Received power/bit & $-68 \mathrm{dBm}$ and $-48 \mathrm{dBm}$ \\
\hline Total Noise Power (Noise figure $=6 \mathrm{~dB})$ & $-101.2 \mathrm{dBm}$ and $-94.6 \mathrm{dBm}$ \\
\hline Required $\mathrm{E}_{\mathrm{b}} / \mathrm{N}_{\mathrm{o}}$ for a bit error rate (BER) of $10^{-6}$ & $3.1 \mathrm{y} 12.52 \mathrm{~dB}$ \\
\hline Fading margin & $10 \mathrm{~dB}$ \\
\hline Implementation and other losses & $14 \mathrm{~dB}$ \\
\hline Link margin & $6.09 \mathrm{~dB}$ and $9.74 \mathrm{~dB}$ \\
\hline
\end{tabular}

Sorce: Modified from (Wang et al., 2010)

The superframe structure consists of 16 frames with time fixed length of $10 \mathrm{~ms}$ each one, and each superframe includes a preamble superframe used for synchronization, a frame preamble used for channel estimation and a control header of a superframe (SCH) (Mody, 2020) to carry the MAC of the carriers of the BS together with the programming of long periods for sensing, and other information about the WRAN cell. In a general view, for the channel classification a flowchart starts looking for incumbents in the database, if they exist, asks for channel availability, if not, ends the cycle. If it does not exist in the database, it must verify for channel availability; if there are available channels, it senses the environment and verifies for availability, sees (Mody, 2020) for more detail of the flowchart. The Table 2 lists the key design features of the MAC layer with a simplified description. The main blocks of the MAC are beaconing and channel access protocols. 


\section{- Sensing manager (SM)}

The main function of the SM is to take decision for managing the channel, this implies a two-step process: i) the SM receives the availability of channels of an external DB that includes the incumbents, and ii) the SM classify the TV channels as available or not available.

Table 2

Features to support key functionality of MAC layer

\begin{tabular}{|l|l|}
\hline \multicolumn{1}{|c|}{ Functionality } & \multicolumn{1}{c|}{ Features } \\
\hline Network formation & Peer to peer, master-to-slave, and mesh \\
\hline Beaconing & Scalable multi-device beaconing \\
\hline Channel access & $\begin{array}{l}\text { High efficient reservation access with } \\
\text { overlay support of prioritized contention } \\
\text { access }\end{array}$ \\
\hline Frame processing & $\begin{array}{l}\text { Frame aggregation and burst transmission } \\
\text { with block ACK }\end{array}$ \\
\hline Spectrum sensing & $\begin{array}{l}\text { Synchronized Quiet Period and Extended } \\
\text { Quiet Zone }\end{array}$ \\
\hline Self-coexistence & $\begin{array}{l}\text { Full interoperability between different device } \\
\text { types. Support channel reservation and QP } \\
\text { schedule across neighboring networks. }\end{array}$ \\
\hline Spectrum agility & $\begin{array}{l}\text { Full interoperability between different device } \\
\text { types. Support channel reservation and QP } \\
\text { schedule across neighboring networks. }\end{array}$ \\
\hline $\begin{array}{l}\text { Transmit power } \\
\text { control (TPC) }\end{array}$ & $\begin{array}{l}\text { Wide-range TPC based on link quality and } \\
\text { incumbent status }\end{array}$ \\
\hline Device discovery & Auto discovery \\
\hline $\begin{array}{l}\text { Power } \\
\text { management }\end{array}$ & $\begin{array}{l}\text { Traffic indication MAP, Hibernate and sleep modes } \\
\text { Sorce: (Wang et al., 2010) }\end{array}$ \\
\hline
\end{tabular}

The available channels are classified as:

- Protected: channel where the incumbent channels or the WRAN operations have been detected through sensing.

- $\quad$ Not classified: channels that are not sensed yet

- Not allowed: precluded channels by the operator due to regulatory or operational restrictions

- Operational: channels under operation for communication between the BS and the CPE inside a WRAN 802.22 cell.

- Backup: cleared channels that become operational channels in the case of WRAN 802.22 that require to switch to other channels.

- Candidates: candidate channel that become a backup channel

\section{Spectrum sensing models}

Different spectrum sensing techniques have been proposed to identify the presence of the PUs signal transmission. These techniques provide more spectrum utilization opportunities to the secondary users (SUs) without generating interference or being intrusive to the PUs. The most common techniques are the energy detector (ED) (Guo et al., 2017), autocorrelation based detection (Reyes et al., 2016), (Subramaniam et al., 2015), Euclidean distance (Reyes et al., 2016), Wavelet (Tian \& Giannakis, 2006), matched filter (Reddy et al., 2019; Salahdine et al., 2015), eigenvalue detection (Schell \& Gardner, 1990; Shakir et al., 2013; W. Zhao et al., 2019), and the cyclostationary detector (A Nafkha et al., 2015), (Gardner, 1988), within others. 
Reviewing the literature all these techniques have been validated experimentally, and the state-of-the-art points towards eigenvalue ratio detector (ERD) involving the ratio of the largest and the smallest eigenvalues and hybrid algorithms that improve significantly the spectrum detection. The important key in the validation stage is related to the probability of detection (PD) and the probability of false alarm (PFA) as functions of the number of samples or the signal to noise ratio (SNR). Besides, the threshold of the proposed methods that are derived using the random matrix theory and statistics test with the moments of the Gaussian/Gamma distribution functions for example. An interesting advantage of the cyclostationary detector regarding the energy and radiometric detectors is the ability for taking signal timing measurements, signal discrimination, and sensitivity reduction in front of uncertainty and changes at the background noise level and interference activity (Gardner, 1988).

It means, the features of the signal are distributed discretely from the frequency cycle into the spectrum cycle, where signals with spectrum overlapping can not exhibit these characteristics in the spectrum cycle. The TV signals have primary features in the frequency cycles at multiples of the sampling rate of the horizontal line ( $15.75 \mathrm{kHz}$ and $15.625 \mathrm{kHz}$ in the USA and Europe, respectively). The modulated OFDM signals (Koffman \& Roman, 2002), have cyclic features in $k /\left(N_{t} T_{b}\right)$, where $k$ is an integer number, $N_{t}$ is the length of the OFDM block (size of the Fast Fourier Transform plus the cyclic prefix), and $T_{b}$ is the symbol length.

\section{Study of Feasibility and Experimental Proof-of-Concept}

As part of the study, an experiment consists of validating as a proof-of-concept the transmission of digital video in back-to-back using two USRP N210. The modulation format was QPSK and the multicarrier signal is OFDM at a frequency carrier of $666 \mathrm{MHz}$. The GNU Radio code implements the OFDM architecture on the transmitter and receiver sides. Figure 3 , shows the experimental setup and a countdown transmission in back-to-back. Like the Colombian NSA has its database of the channel used and available, a request of channels available in the hill of Manjuy allows performing a spectrum sounding implemented by the energy detector to find white spaces (TV channels) free of use in the surrounding area.

Figure 3

Experimental setup for digital video transmission using USRP N210

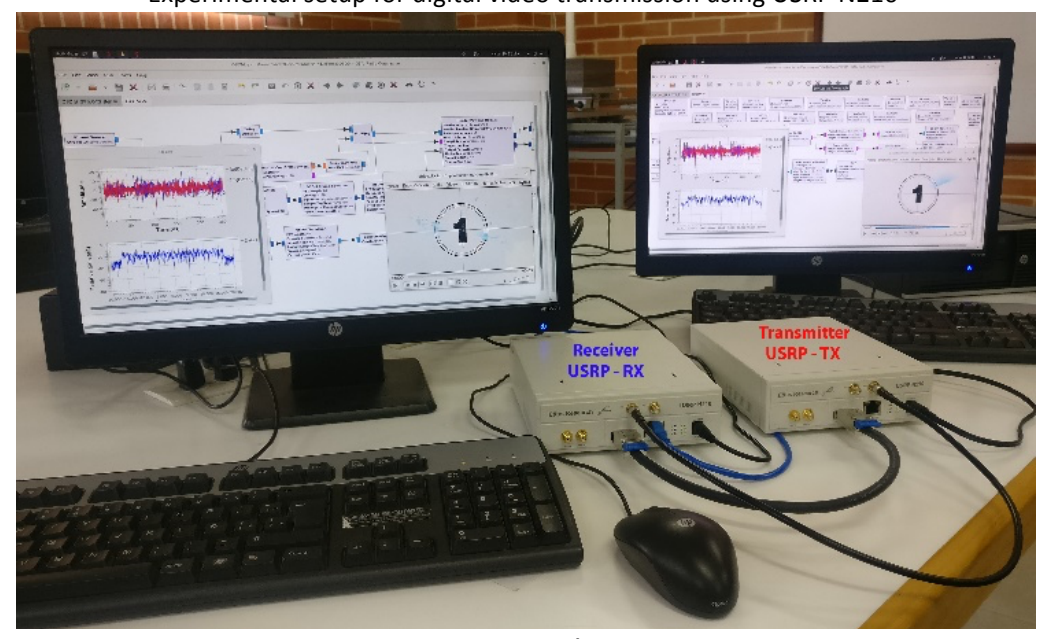

Source: Authors

To avoid interference with PUs and as a test, the USRP was connected directly through the MIMO cable and executed from the transmitter computer. A point-to-multipoint system is evaluated using Radio Mobile, a radio wave propagation prediction tool dedicated to amateur radio to understand the signal propagation and coverage over the area. 
Five different technologies of TVWS including the providers Adaptrum, Carlson, Redline, and Metric Systems, were evaluated considering the regulation of the Colombian NSA based on database TVWS technology. The datasheet with the specs is summarized in Table III. Different data rate performance depends on the available channel bandwidth (6-8 $\mathrm{MHz}$ and with expansion up to $10 \mathrm{MHz}$ ) that enable data rates from 46 up to $81 \mathrm{Mbps}$. The modulation formats can be QPSK, 16-QAM, 64- maximum QAM, and 256-QAM, some of them require specific coding rates, related to the error correction schemes of the equipment. Besides, each radio must incorporate management for geolocalization using a global positioning system (GPS), and the resource allocation (availability of channels) can be dynamic. Also, the technical specs show the maximum power consumption, and the radio supports Power Over Ethernet (POE) that can be useful if there is no power supply or intermittent failure in the base station. On the other hand, some irradiant systems (antennas) are suggested with their polarization type and appropriate gains to achieve the maximum efficiency of the system. The bandwidth of the antennas must cover the $470-698 \mathrm{MHz}$ band, also, drive vertical and horizontal polarization and must to have a standing wave ratio (SWR) slightly higher than unity with a matching impedance of $50 \Omega$, gains higher than $7.5 \mathrm{dBi}$ and must complain of environmental regulation such as the IP67. Its building material can be aluminum covered by polyester or Steel No. 316, within others.

Table 3

Provider technical solutions for TVWS technology

\begin{tabular}{|c|c|c|c|c|c|c|c|c|c|c|c|c|c|}
\hline Brand & Model & $\begin{array}{l}\text { Coverage } \\
\text { angle }^{\circ}\end{array}$ & $\begin{array}{l}\text { Distance } \\
(\mathrm{km})\end{array}$ & $\begin{array}{l}\text { Max. } \\
\text { power } \\
\text { (dBm) }\end{array}$ & $\begin{array}{c}\text { Required } \\
\text { power } \\
\text { (W) }\end{array}$ & $\begin{array}{l}\text { Antena } \\
\text { gain } \\
\text { (dBi) } \\
\end{array}$ & $\begin{array}{l}\text { Coding and } \\
\text { modulation }\end{array}$ & $\begin{array}{l}\text { Efficiency } \\
\text { (\%) }\end{array}$ & $\begin{array}{l}\text { Frequency } \\
\text { operation }\end{array}$ & $\begin{array}{l}\text { External antenna } \\
\text { options }\end{array}$ & $\begin{array}{l}\text { Coverage } \\
\text { sectors }\end{array}$ & $\begin{array}{c}\text { Coverage } \\
\text { area } \\
\left(\mathrm{km}^{2}\right) \\
\end{array}$ & Standard \\
\hline Adaptrum & $\begin{array}{l}\text { ACRS2- } \\
\text { B2000 }\end{array}$ & 360 & 10 & $\begin{array}{l}200 \mathrm{~mW} \\
(23 \mathrm{dBm})\end{array}$ & 42 & 11 & $\begin{array}{l}\text { 256-QAM } \\
\text { (Low } \\
\text { Latncy) } \\
\text { QPSK, } \\
\text { 16QAM, } \\
\text { 64QAM }\end{array}$ & $94 \%$ & $\begin{array}{c}400 \mathrm{MHz}- \\
1 \mathrm{GHz}\end{array}$ & $\begin{array}{c}\text { Log- } \\
\text { Periodic:Vertically } \\
\text { polarized } 65^{\circ}, \\
11 \mathrm{dBi} \text { Panel } \\
\text { Antnna: polarized } \\
90^{\circ}, 11 \mathrm{dBi}\end{array}$ & 3 & 300 & $N / R$ \\
\hline Carlson & $\begin{array}{c}\text { Gen } 3 \\
\text { Rural } \\
\text { Connect }\end{array}$ & 360 & 25 & $21 \mathrm{dBm}$ & 20 & 10.3 & $\begin{array}{c}\text { QPSK } 3 / 4, \\
16 Q A M \\
3 / 4, \\
64 Q A M \\
5 / 6, \\
256 Q A M \\
5 / 6\end{array}$ & $94 \%$ & $\begin{array}{l}\text { UHF } 470- \\
696 \mathrm{MHz}\end{array}$ & $\begin{array}{l}3 \text { F-type female } \\
75 \mathrm{Ohms}\end{array}$ & 3 & $300-700$ & $\begin{array}{c}\text { IEEE } \\
802.11 \text { af }\end{array}$ \\
\hline Redline & $\begin{array}{l}\text { Enterprises } \\
\text { CPE/XR }\end{array}$ & $\mathrm{N} / \mathrm{R}$ & $\mathrm{N} / \mathrm{R}$ & $\mathrm{N} / \mathrm{R}$ & 12 & 22 & $\begin{array}{c}\text { BPSK to } \\
256 \text { QAM } \\
7 / 81\end{array}$ & $93 \%$ & $\begin{array}{c}3300- \\
3800 \mathrm{MHz}\end{array}$ & $\mathrm{N} / \mathrm{R}$ & $\mathrm{N} / \mathrm{R}$ & $\mathrm{N} / \mathrm{R}$ & $\begin{array}{c}\text { IEEE } \\
802.11 \text { at }\end{array}$ \\
\hline $\begin{array}{l}\text { Raptor - } \\
\text { XR }\end{array}$ & $\begin{array}{c}\text { UHF } \\
\text { RaptorXR } \\
\# 50739.1 \\
\text { P.470 }\end{array}$ & $\mathrm{N} / \mathrm{R}$ & 8.04 & $36 \mathrm{dBm}$ & 10 & 17.15 & $\begin{array}{l}\text { 4QAM } \\
\text { CR:1/ } \\
\text { GI:1/2 }\end{array}$ & $N / R$ & $\begin{array}{c}470-698 \\
\mathrm{MHz}\end{array}$ & $\mathrm{N} / \mathrm{R}$ & $N / R$ & $\mathrm{~N} / \mathrm{R}$ & $N / R$ \\
\hline Carlson & $\begin{array}{c}\text { Rural } \\
\text { Connect } \\
\text { Gen II }\end{array}$ & $\mathrm{N} / \mathrm{R}$ & $\mathrm{N} / \mathrm{R}$ & $28 \mathrm{dBm}$ & 24 & 4.8 & $\begin{array}{l}\text { QPSK, } \\
\text { 16QAM }\end{array}$ & $N / R$ & $\begin{array}{l}\text { UHF } 470- \\
789 \mathrm{MHz}\end{array}$ & $\mathrm{N} / \mathrm{R}$ & $\begin{array}{l}\text { 3 F-type } \\
\text { female } \\
75 \text { Ohms }\end{array}$ & $\mathrm{N} / \mathrm{R}$ & $N / R$ \\
\hline
\end{tabular}

Source: Authors

Besides, a key aspect is related to the antenna location, if the installation is allowed in a tower infrastructure or post. The antenna together with the radio power transmission delivers the EIRP and depends on the maximum power that supports the transmitter and the antenna. The equipment presented in Table 3, can cover a military base of approximately $300 \mathrm{~km}^{2}$, with a transmission power of $8 \mathrm{~W}$ and up $25 \mathrm{~W}$, and antenna gains of maximum $17.15 \mathrm{dBi}$, for ensuring long path propagation of electromagnetic waves.

\section{Conclusions}

This paper presents a general review of the WRAN IEEE 802.22 standard to know and understand the different technical specs that allow selecting a technical solution in connectivity access for the Colombian National Army in the hill of Manjuy near to Facatativá city. Some specific parameters can not be published for security reason but a trial on digital video transmission was carried-out to understand the feasibility. From the table, the equipment Carlson Gen 3 Rural Connect provides compliance with the IEEE 802.11af standard and the other technical parameters achieve the requirements in terms of efficiency and budget. Low power transmission and a full variety of modulation formats with coding in the range of $470-696 \mathrm{MHz}$ provide omnidirectional coverage 
in a range of up to $700 \mathrm{~km} 2$. The state of the art suggests important improvements using the eigenvalue ratio detector in the spectrum sensing if the database assisted TVWS is not available and the dynamic spectrum allocation is enabled. Future work will focus on the test and compare different spectrum detection techniques validating using the USRP radios.

\section{Acknowledgment}

The authors thank the Escuela de Comunicaciones and the Grupo de Investigación en Comunicaciones Militares (ESCOM) of the Colombian Army located Facatitiva city, and the INFELCOM and GINTEL Research Groups of the Universidad Pedagógica y Tecnológica de Colombia for the financial support during this research work.

\section{References}

Alsharbaty, F. S., Ali, O. M., \& Sheet, Y. S. (2019). Estimating the consuming resources of IEEE 802.16e cell in case of video conference application. IOP Conference Series: Materials Science and Engineering, 518, 52009. https://doi.org/10.1088/1757-899x/518/5/052009

Anabi, K. H., Nordin, R., \& Abdullah, N. F. (2016). Database-Assisted Television White Space Technology: Challenges, Trends and Future Research Directions. IEEE Access, 4, 8162-8183. https://doi.org/10.1109/ACCESS.2016.2621178

Borth, D., Ekl, R., Oberlies, B., \& Overby, S. (2008). Considerations for Successful Cognitive Radio Systems in US TV White Space. 2008 3rd IEEE Symposium on New Frontiers in Dynamic Spectrum Access Networks, 1-5. https://doi.org/10.1109/DYSPAN.2008.61

FCC, B. of E. \& T. (2019). Amendment of Part 15 Rules for Unlicensed White Spaces Devices. https://www.fcc.gov/document/amendment-part-15-rules-unlicensed-white-spaces-devices

Gardner, W. A. (1988). Signal interception: a unifying theoretical framework for feature detection. IEEE Transactions on Communications, 36(8), 897-906. https://doi.org/10.1109/26.3769

Guo, H., Jiang, W., \& Luo, W. (2017). Linear Soft Combination for Cooperative Spectrum Sensing in Cognitive Radio Networks. IEEE Communications Letters, 21(7), 1573-1576. https://doi.org/10.1109/LCOMM.2017.2686393

Gurney, D., Buchwald, G., Ecklund, L., Kuffner, S. L., \& Grosspietsch, J. (2008). Geo-Location Database Techniques for Incumbent Protection in the TV White Space. 2008 3rd IEEE Symposium on New Frontiers in Dynamic Spectrum Access Networks, 1-9. https://doi.org/10.1109/DYSPAN.2008.31

Haykin, S. (2005). Cognitive radio: brain-empowered wireless communications. IEEE Journal on Selected Areas in Communications, 23(2), 201-220. https://doi.org/10.1109/JSAC.2004.839380

Ko, C.-H., Huang, D. H., \& Wu, S. (2011). Cooperative spectrum sensing in TV White Spaces: When Cognitive Radio meets Cloud. 2011 IEEE Conference on Computer Communications Workshops (INFOCOM WKSHPS), 672-677. https://doi.org/10.1109/INFCOMW.2011.5928897

Koffman, I., \& Roman, V. (2002). Broadband wireless access solutions based on OFDM access in IEEE 802.16. IEEE Communications Magazine, 40(4), 96-103. https://doi.org/10.1109/35.995857

Martin, F. L., Correal, N. S., Ekl, R. L., Gorday, P., \& O’Dea, R. (2008). Early Opportunities for Commercialization of TV Whitespace in the U.S. 2008 3rd International Conference on Cognitive Radio Oriented Wireless 
Networks and Communications (CrownCom 2008), 1-5.

https://doi.org/10.1109/CROWNCOM.2008.4562539

Masonta, M. T., Mzyece, M., \& Mekuria, F. (2012). A Comparative Study of Cognitive Radio Platforms.

Proceedings of the International Conference on Management of Emergent Digital EcoSystems, 145-149. https://doi.org/10.1145/2457276.2457301

Mitola, J., \& Maguire, G. Q. (1999). Cognitive radio: making software radios more personal. IEEE Personal Communications, 6(4), 13-18. https://doi.org/10.1109/98.788210

Mody, A. (2020). IEEE Standard for Information technology-- Local and metropolitan area networks-- Specific requirements-- Part 22: Cognitive Wireless RAN Medium Access Control (MAC) and Physical Layer (PHY) specifications: Policies and procedures for operation in the TV. In IEEE Std 802.22-2011 (pp. 1-680). https://doi.org/10.1109/IEEESTD.2011.5951707

Morelli, M., Kuo, C.-. J., \& Pun, M. (2007). Synchronization Techniques for Orthogonal Frequency Division Multiple Access (OFDMA): A Tutorial Review. Proceedings of the IEEE, 95(7), 1394-1427. https://doi.org/10.1109/JPROC.2007.897979

Nafkha, A, Naoues, M., Cichony, K., Kliks, A., \& Aziz, B. (2015). Hybrid spectrum sensing experimental analysis using GNU radio and USRP for cognitive radio. 2015 International Symposium on Wireless Communication Systems (ISWCS), 506-510. https://doi.org/10.1109/ISWCS.2015.7454395

Nafkha, Amor. (2011). Software Defined Radio Platform for Cognitive Radio: Design and Hierarchical Management (C. Moy (ed.); p. Ch. 15). IntechOpen. https://doi.org/10.5772/18267

Nekovee, M. (2010). Cognitive Radio Access to TV White Spaces: Spectrum Opportunities, Commercial Applications and Remaining Technology Challenges. 2010 IEEE Symposium on New Frontiers in Dynamic Spectrum (DySPAN), 1-10. https://doi.org/10.1109/DYSPAN.2010.5457902

Reddy, A. A., Battula, R. B., Gopalani, D., \& Kurra, C. (2019). An adaptive threshold energy detection mechanism using GNU Radio on USRP. 2019 11th International Conference on Communication Systems \& Networks (COMSNETS), 251-258. https://doi.org/10.1109/COMSNETS.2019.8711312

Reyes, H., Subramaniam, S., Kaabouch, N., \& Hu, W. C. (2016). A spectrum sensing technique based on autocorrelation and Euclidean distance and its comparison with energy detection for cognitive radio networks. Computers \& Electrical Engineering, 52, 319-327. https://doi.org/https://doi.org/10.1016/j.compeleceng.2015.05.015

Salahdine, F., Ghazi, H. E., Kaabouch, N., \& Fihri, W. F. (2015). Matched filter detection with dynamic threshold for cognitive radio networks. 2015 International Conference on Wireless Networks and Mobile Communications (WINCOM), 1-6. https://doi.org/10.1109/WINCOM.2015.7381345

Schell, S. V, \& Gardner, W. A. (1990). Detection of the Number of Cyclostationary Signals in Unknown Interference and Noise. 1990 Conference Record Twenty-Fourth Asilomar Conference on Signals, Systems and Computers, 1990., 1, 473. https://doi.org/10.1109/ACSSC.1990.523382

Shakir, M. Z., Rao, A., \& Alouini, M. (2013). Generalized Mean Detector for Collaborative Spectrum Sensing. IEEE Transactions on Communications, 61(4), 1242-1253. https://doi.org/10.1109/TCOMM.2013.13.110594 
Subramaniam, S., Reyes, H., \& Kaabouch, N. (2015). Spectrum occupancy measurement: An autocorrelation based scanning technique using USRP. 2015 IEEE 16th Annual Wireless and Microwave Technology Conference (WAMICON), 1-5. https://doi.org/10.1109/WAMICON.2015.7120376

Tian, Z., \& Giannakis, G. B. (2006). A Wavelet Approach to Wideband Spectrum Sensing for Cognitive Radios. 2006 1st International Conference on Cognitive Radio Oriented Wireless Networks and Communications, 1-5. https://doi.org/10.1109/CROWNCOM.2006.363459

Wang, J., Song, M. S., Santhiveeran, S., Lim, K., Ko, G., Kim, K., Hwang, S. H., Ghosh, M., Gaddam, V., \& Challapali, K. (2010). First Cognitive Radio Networking Standard for Personal/Portable Devices in TV White Spaces. 2010 IEEE Symposium on New Frontiers in Dynamic Spectrum (DySPAN), 1-12. https://doi.org/10.1109/DYSPAN.2010.5457855

Zhao, Q., \& Sadler, B. M. (2007). A Survey of Dynamic Spectrum Access. IEEE Signal Processing Magazine, 24(3), 79-89. https://doi.org/10.1109/MSP.2007.361604

Zhao, W., Li, H., Jin, M., \& Yoo, S. (2019). Maximum Eigenvalue and Energy Combined Spectrum Sensing Algorithm. 2019 International Conference on Engineering and Telecommunication (EnT), 1-5. https://doi.org/10.1109/EnT47717.2019.9030568

Esta obra está bajo una Licencia Creative Commons

Attribución-NoCommercial 4.0 International

\section{(cc) EY-NC}

